\title{
Concomitant laparoscopic sleeve gastrectomy and laparoscopic cholecystectomy in a morbidly obese patient with situs inversus totalis
}

Volkan Yigit ${ }^{1}$, Kenan Binnetoglu², Mürşit Dincer ${ }^{3}$

${ }^{1}$ Department of General Surgery, Memorial Hospital, Diyarbakir, Turkey 2Department of General Surgery, Kafkas University Hospital, Kars, Turkey ${ }^{3}$ Department of General Surgery, Firat University Hospital, Elazig, Turkey

Submitted: 13 November 2020

Accepted: 7 February 2020

Arch Med Sci Civil Dis 2021; 6: e8-e11

DOI: https://doi.org/10.5114/amscd.2021.105387

Copyright 2021 Termedia \& Banach

Situs inversus totalis (SIT) is a rare congenital condition in which the major visceral organs within the thorax and abdomen are reversed from their normal positions. Its incidence is 1 in 10 000-50 000 of the population [1]. It presents difficulties in laparoscopic surgery, because of the mirror-image anatomy. Laparoscopic surgical treatments of some conditions in patients with situs inversus totalis such as acute appendicitis, cholelithiasis, and morbid obesity have been previously reported [2-4].

Herein we report a case of situs inversus totalis treated with concomitant laparoscopic sleeve gastrectomy (LSG) and laparoscopic cholecystectomy (LC).

A 28 -year-old woman who had a body mass index $46.9 \mathrm{~kg} / \mathrm{m}^{2}$ was electively admitted to the department of general surgery for LSG. She had a history of myringotomy for otitis media in childhood. She had situs inversus totalis diagnosis at that time. Physical examination revealed the apex beat on the right side. Chest X-ray from the posteroanterior view demonstrated dextrocardia (Figure 1). Preoperative abdominal ultrasonography also confirmed SIT and revealed cholelithiasis. Laboratory profiles were normal. It was decided to perform concomitant LSG and LC.

The patient was positioned in the reverse Trendelenburg position with two video monitors at the shoulder on both sides of the patient after general anesthesia. The surgeon stood between the patient's legs to provide the most ergonomically advantageous position for access to both upper quadrants of the abdominal cavity. A 10-mm camera port was inserted using a bladeless optical trocar $2 \mathrm{~cm}$ above the umbilicus. Pneumoperitoneum with $\mathrm{CO}_{2}$ was established with a pressure of $12 \mathrm{~mm}$ $\mathrm{Hg}$. A thirty degree viewing laparoscope was introduced through this port. The laparoscope confirmed situs inversus totalis (Figure 2). Two 12$\mathrm{mm}$ trocars were inserted $6 \mathrm{~cm}$ below the subcostal margin in the right and left upper quadrants along the midclavicular line. A 5-mm trocar was inserted in the right upper quadrant subcostal area along the anterior axillary line. Another 5-mm trocar was inserted in the subxiphoid area for the Nathanson liver retractor (Figure 3). The gastrocolic ligament was dissected to the stomach to $4 \mathrm{~cm}$ from the pylorus. The curvature major was dissected to the angle of His with an electrothermal bipolar vessel sealing device (Ligasure, Covidien IIc, MA, USA). Traction of the stomach was carried out by the surgeon's right hand, and vessel sealing was carried out by the left hand. A 39-French orogastric tube passed

\author{
Corresponding author: \\ Mürşit Dincer \\ Department of \\ General Surgery \\ Firat University Hospital \\ Elazig, Turkey \\ Phone: +905446422820 \\ E-mail: drmursitdincer@ \\ gmail.com
}




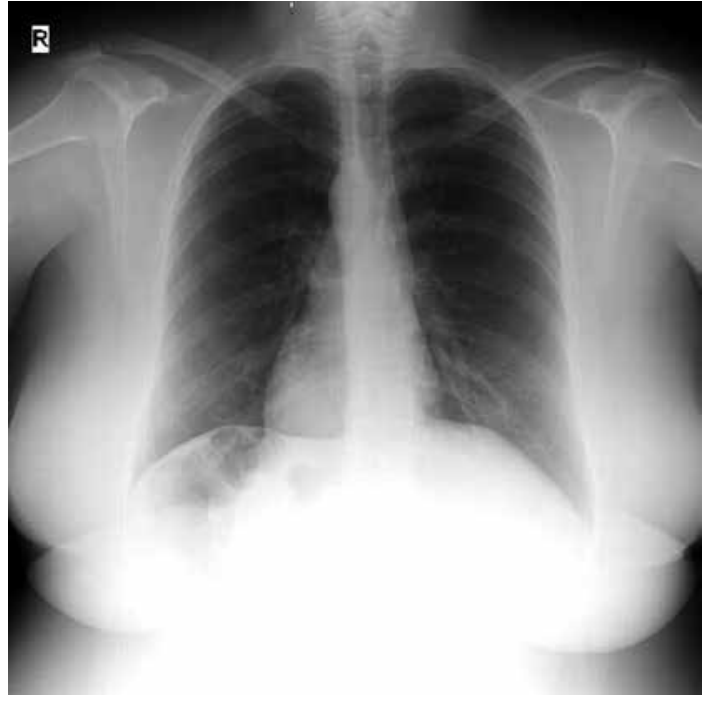

Figure 1. Chest X-ray confirmed dextrocardia

into the stomach for remnant gastric calibration. The stomach was divided parallel to the orogastric tube along the curvature minor of the stomach using an Echelon stapler (Ethicon, Cincinnati, OH, USA). After a leakage test using methylene blue, fibrin sealant (Tisseel, Baxter, Glendale, CA, USA) was applied onto the staple line of the remaining stomach. This stage of the operation lasted $48 \mathrm{~min}$, and it was not more difficult than in patients with normally sited intra-abdominal organs. Then, the Nathanson liver retractor was taken out from abdominal cavity and a 5-mm trocar was re-placed in the subxiphoid area. A window was created on the falciform ligament. Upward traction of the gallbladder fundus was carried out by a grasper inserted into the left upper quadrant via this window (Figure 4). The surgeon used his right hand to retract the neck of the gallbladder and

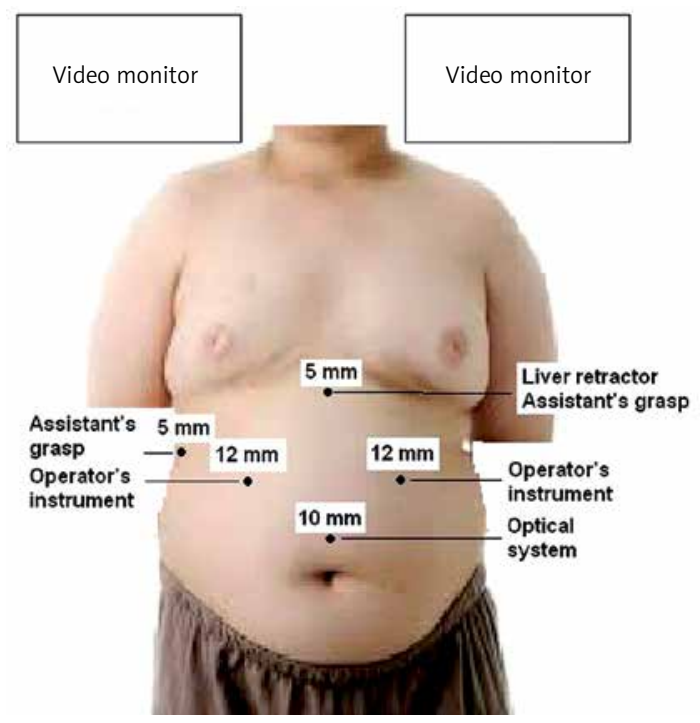

Figure 3. Insertion of the trocars

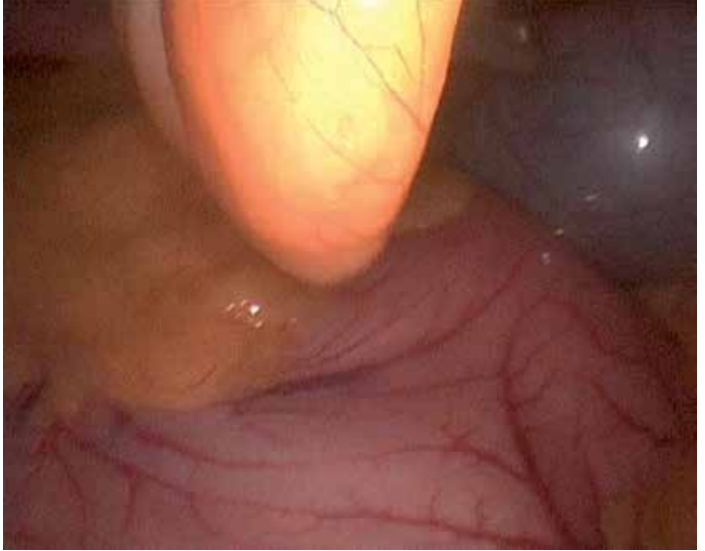

Figure 2. Laparoscopic exploration

used his left hand to dissect Calot's triangle. The dissection of Calot's triangle was easily carried out. The cystic duct and artery were identified. There were no structural abnormalities in these structures. Both of them were clipped and then divided. After division of all peritoneal reflections on either side, the gallbladder was retrogradely separated from the liver bed using hook-electrocautery and Ligasure. This part of the dissection was more difficult than the dissection of Calot's triangle for the surgeon, because the pendulous falciform ligament entering the field of view made it difficult to dissect the medial peritoneal reflection of the gallbladder (Figure 5). However, LC was completed within 27 min without any complications. A drain was placed in contact with the staple line of the remaining stomach. The muscles and aponeurosis of the port sites $12 \mathrm{~mm}$ were closed by a suture passer device. Total time was $86 \mathrm{~min}$.

The postoperative period was uneventful. A water-soluble upper gastrointestinal contrast study was performed to detect leakage on the second postoperative day. There was no leakage and the patient was allowed a liquid diet. She was discharged on the fifth day. No complications have emerged after a 3-month follow-up period. Weight loss was $27 \mathrm{~kg}$ (48\% of excess weight).

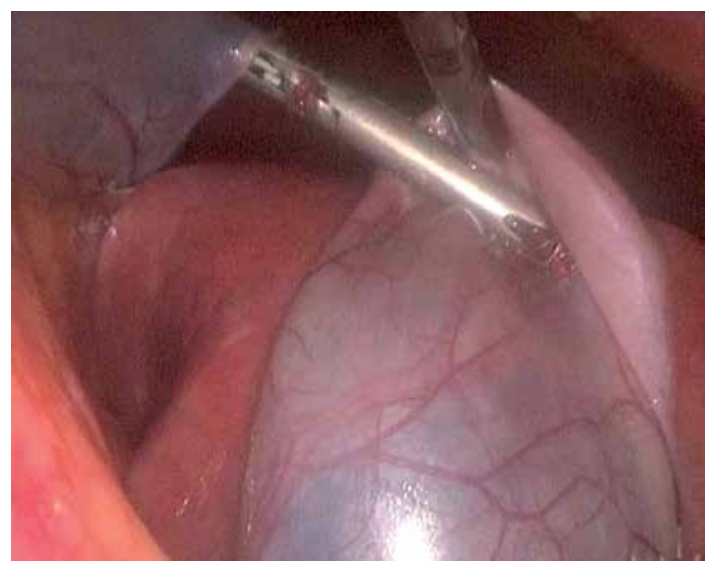

Figure 4. Laparoscopic cholecystectomy 


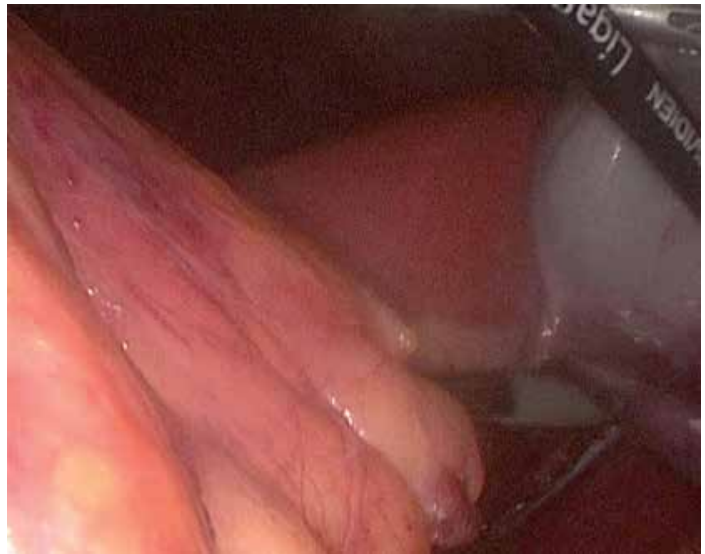

Figure 5. Dissection of the medial peritoneal reflection of gallbladder

Situs inversus totalis is a very rare autosomal recessive entity [5]. It can be easily diagnosed after chest X-ray, abdominal sonography or computed tomography. For the present case, the pre-operative diagnosis of situs inversus totalis was made by chest X-ray and abdominal ultrasound. Some abnormalities such as cardiovascular or respiratory may be associated with situs inversus totalis [4], but our patient has no other abnormalities.

Situs inversus totalis is not a contraindication to laparoscopic surgery. However, it can present difficulties in laparoscopic surgery, because of the mirror-image anatomy. Right handed surgeons may have to use their left hand for dissection. However, this technical difficulty does not make it impossible to complete the operation laparoscopically.

Laparoscopic cholecystectomy is the gold standard for treating symptomatic cholelithiasis [6]. Five additional LC procedure in patients with situs inversus have been reported since the review of the literature by Salama et al., who reviewed the first 50 cases in the literature [3,7-11]. The general consensus is that the LC will be longer than in a patient with a normally located gallbladder; the need to redirect the visual-motor skills of the surgeon and the cameraman to the left upper quadrant along with the difficulty in skeletonizing Calot's triangle is responsible for the longest portion of the extra-operative time [12]. The reported cases of concomitant laparoscopic procedures for different organs in patients with SIT are extremely rare [5, 13-15].

Laparoscopic sleeve gastrectomy accounts for approximately $30 \%$ of bariatric procedures performed worldwide; and its coexistence with partial situs inversus is one in a million [16]. There are only five reported cases of LSG in a patient with situs inversus in the literature [4, 16-18]. To date, there is no report about a patient with SIT who underwent concomitant LSG and LC. In the present case, we had no need to insert any extra trocar for LC. Dissection of the medial peritoneal reflection of the gallbladder was more difficult than dissection of Calot's triangle. The only factor that complicated the dissection of the gallbladder was the pendulous falciform ligament entering the field of view.

In conclusion, concomitant LSG and LC procedures in a patient with situs inversus totalis are more difficult than standard procedures. However, they can be performed safely without the need for extra trocar insertion.

\section{Conflict of interest}

The authors declare no conflict of interest.

\section{References}

1. Haruki T, Maeta Y, Nakamura S, et al. Advanced cancer with situs inversus totalis associated with KIF3 complex deficiency: report of two cases. Surg Today 2010; 40: 162-6.

2. Akbulut S, Caliskan A, Ekin A, Yagmur Y. Left-sided acute appendicitis with situs inversus totalis: review of 63 published cases and report of two cases. J Gastrointest Surg 2010; 14: 1422-8.

3. Raghuveer MN, Mahesh Shetty S, Sunil Kumar BB. Laparoscopic cholecystectomy in situs inversus totalis. J Clin Diagn Res 2014; 8: 3-5.

4. Catheline JM, Fysekidis M, Dbouk R, et al. Weight loss after sleeve gastrectomy in superobesity. J Obes 2012; 2012: 959260.

5. Taskin M, Zengin K, Ozben V. Concomitant laparoscopic adjustable gastric banding and laparoscopic cholecystectomy in a super-obese patient with situs inversus totalis who previously underwent intragastric balloon placement. Obes Surg 2009; 19: 1724-6.

6. Suter M, Meyer A. A 10-year experience with the use of laparoscopic cholecystectomy for acute cholecystitis: is it safe? Surg Endosc 2001; 15: 1187-92.

7. Zhang SN, Li L, Ran JH, et al. Laparoscopic cholecystectomy in situs inversus totalis: a case report. Chin Med Sci J 2013; 28: 245-7.

8. Khiangte E, Newme I, Patowary K, Phukan P. Single-port laparoscopic cholecystectomy in situs inversus totalis using the E.K. glove port. J Minim Access Surg 2013; 9: 180-2.

9. Ali MS, Attash SM. Laparoscopic cholecystectomy in a patient with situs inversus totalis: case report with review of literature. BMJ Case Rep 2013; 2013: bcr2013201231.

10. Arya SV, Das A, Singh S, et al. Technical difficulties and its remedies in laparoscopic cholecystectomy in situs inversus totalis: a rare case report. Int I Surg Case Rep 2013; 4: 727-30.

11. Salama IA, Abdullah MH, Houseni M. Laparoscopic cholecystectomy in situs inversus totalis: feasibility and review of literature. Int J Surg Case Rep 2013; 4: 711-5.

12. Yaghan RJ, Gharaibeh KI, Hammori S. Feasibility of laparoscopic cholecystectomy in situs inversus. J Laparoendosc Adv Surg Techn A 2001; 11: 233-7.

13. Borgaonkar VD, Deshpande SS, Kulkarni VV. Laparoscopic cholecystectomy and appendicectomy in situs inversus totalis: a case report and review of literature. J Minim Access Surg 2011; 7: 242-5. 
14. Djoha RS, Rodriguez HE, Wieman IM, Unti JA, Podbielsky FJ. Laparoscopic cholecystectomy and appendectomy in situs inversus totalis. JSLS 2000; 4: 251-4.

15. Seo KW, Yoon KY. Laparoscopy-assisted distal gastrectomy for early gastric cancer and laparoscopic cholecystectomy for gallstone with situs inversus totalis: a case report. J Korean Surg Soc 2011; 81: 34-8.

16. Borude S, Jadhav S, Shaikh T, Nath SR. Laparoscopic sleeve gastrectomy in partial situs inversus. J Surg Case Rep 2012; 2012: 8.

17. Sugunakara Rao K. Laparoscopic vertical sleeve gastrectomy after open gastric banding in a patient with situs inversus totalis. J Minim Access Surg 2013; 9: 145-6.

18. Deutsch GB, Gunabushanam V, Mishra N, Sathyanarayana SA, Kamath V, Buchin D. Laparoscopic vertical sleeve gastrectomy after open gastric banding in a patient with situs inversus totalis. J Minim Access Surg 2012; 8: 93-6. 